\title{
PEIEH3MU
}

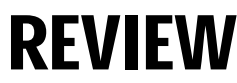

УДК 340:167/168; 001.11; 001.2; 001.4 - 001.6; 001.8; 001.92:37; 340.115; 340.113.1

DOI 10.18413/2712-746X-2020-44-2-385-388

\section{Тематический горизонт методологии научных исследований и прикладной аналитики: \\ рецензия на учебник И.В. Понкина и А.И. Редькиной \\ «Методология научных исследований и прикладной аналитики», 2020}

\author{
Морева С.Л. \\ Санкт-Петербургский государственный университет аэрокосмического приборостроения, \\ Россия, 190000, Санкт-Петербург, ул. Большая Морская, д. 67, лит. А \\ E-mail: sweetmoreva@yandex.ru
}

\begin{abstract}
Аннотация. Автор рецензии обращает внимание на значение разграничения науки и прикладной аналитики и объяснения сути, топологии и онтологии аналитики, сделанного в учебнике. Рецензент обращает внимание на высококачественные авторские объяснения методов научных исследований и прикладной аналитики. По мнению рецензента, заслуживает внимания и представляет интерес глубоко раскрытая в учебнике проблема формирования академической научной культуры и обучения академическому научному письму в российском образовании и науке. Рецензент делает вывод о том, что указанный учебник может быть полезен всем, кто интересуется обозначенным тематическим горизонтом, - от студентов вузов до научных работников и профессорско-преподавательского состава образовательных организаций.
\end{abstract}

Ключевые слова: научное исследование, прикладная аналитика, научная подготовка, методы исследования, научный язык, наука.

Для цитирования: Морева С.Л. 2020. Тематический горизонт методологии научных исследований и прикладной аналитики: рецензия на учебник И.В. Понкина и А.И. Редькиной «Методология научных исследований и прикладной аналитики». NOMOTHETIKА: Философия. Социология. Право. 45 (2): 385-388. DOI 10.18413/2712-746X-2020-44-2-385-388

\section{Thematic horizon of research methodology and applied analytics: \\ review on the textbook of I.V. Ponkin and A.I. Redkina «Methodology of scientific research and practical analytics»}

\author{
Svetlana L. Moreva \\ Saint-Petersburg State University of Aerospace Instrumentation, \\ SUAI, 67, Bolshaya Morskaia str., Saint-Petersburg, 190000, RUSSIA \\ E-mail: sweetmoreva@yandex.ru
}

Abstract. This material is a review of the textbook «Methodology of Scientific Research and Practical Analytics. Textbook» by I.V. Ponkin and A.I. Redkina (2020). The review emphasizes the importance of scientific and applied analytical training of novice researchers. The authors review draws attention to the 
importance of distinguishing the science and the applied analytics and explaining the essence, topology and ontology of analytics made in the textbook. The reviewer draws attention to high-quality author's explanations (given by the authors of the textbook) of research methods and applied analytics. According to the reviewer, the problem of forming an academic scientific culture and teaching academic scientific writing in Russian education and science, which is deeply revealed in the textbook, deserves attention and is of interest. The reviewer concludes that this textbook can be useful to everyone who is interested in the indicated thematic horizon, from university students to researchers and faculty of educational organizations.

Keywords: scientific research, applied analytics, scientific education, research methods, scientific language, science.

For citation: Moreva S.L. 2020. Thematic horizon of research methodology and applied analytics: review on the textbook of I.V. Ponkin and A.I. Redkina «Methodology of scientific research and practical analytics». NOMOTHETIKA: Philosophy. Sociology. Law series. 45 (2): 385-388 (in Russian). DOI 10.18413/2712-746X-2020-44-2-385-388

В условиях, когда вокруг так много говорится о науке и прикладной аналитике, самое время обратиться к литературе об этом. Как гласит полушутливая поговорка, хороший автор отличается от плохого тем, что хороший автор пишет хорошо, а плохой - плохо. С этого лирического вступления мы начнем изложение наших размышлений, спровоцированных и навеянных учебником «Методология научных исследований и прикладной аналитики» авторства д.ю.н., проф. И.В. Понкина и к.ю.н. А.И. Редькиной в части, касающейся комплекса вопросов, связан-ных с мерой должного в подготовке магистрантов, аспирантов и докторантов и с крите-риальной шкалой, позволяющей замерять и оценивать меры научных качеств исследова-ния, чтобы, как образно говорится, отделять пшеницу от мякины (остатков колосьев, стеблей и т.п. при молотьбе).

Обозреваемый учебник, увидевший свет в 2020 году в издательстве «Буки Веди», адресован, как гласит аннотация на с. 2, руководителям и сотрудникам научных организаций, руководителям и сотрудникам аналитических центров (организаций, подразделений), научным работникам и профессорско-преподавательскому составу образовательных организаций, заказчикам и потребителям прикладных аналитических и научных произведений (продуктов), аспирантам и докторантам, студентам вузов, а также всем тем, кто интересуется обозначенным тематическим горизонтом. Учебник продолжает вышедшее годом ранее издание тех же авторов «Цитирование как метод сопровождения и обеспечения научного исследования».

Целых пять рецензентов, указанных на второй странице издания, одни доктора наук - три юридических, по одному - технических и педагогических наук, - всё это тоже характеризует данное издание вполне определённым позитивным образом, но в числе прочего как качественное универсальное издание. От себя, как представителя технических наук, добавлю, что издание вовсе не «закольцовано» на юристов, является (и по содержанию, и по лексике, и по привязкам) более чем актуальным, релевантным и интересным и для представителей куста (укрупнённой отрасли) технических наук. Впрочем, это неудивительно, поскольку один из авторов (И.В. Понкин) имеет, помимо высшего юридического, ещё и отличное высшее инженерное образование. Часть содержания учебника непосредственно связана с собственными научными интересами автора настоящей рецензии. И я нахожу, что учебник лично мне даёт много полезного.

Очень важным является обращение авторов к этому тематическому горизонту - о том, как и какими методиками готовить будущих ученых исследователей и прикладных аналитиков (авторы достаточно убедительно разводят эти две сферы умственной творческой деятельности). Эта проблема стоит сегодня перед всей российской наукой, пожинающей плоды многих десятилетий дурного публичного управления наукой и, в числе про- 
чего, плоды, по сути, «обожествления» двух англо-американских коммерческих систем индексации журнальных и сборниковых статей, плоды постановки ученых под власть завхозов и бухгалтеров, что не могло не привести к печальным последствиям. Повальная именно научно-методологическая безграмотность убивает перспективы российской науки, препятствует приходу в науку светлых головушек из числа молодёжи. Качественных учебников и пособий по обучению технологиям науки - на всю страну лишь несколько штук.

Между тем, не подлежит дискуссии аксиома о том, что будущих исследователей следует на серьезном уровне, высококачественно учить этому искусству - искусству исследования (научного ли, или же прикладного аналитического), познания и осмысления, поиска, сбора и обработки научной информации.

Перед нами актуальнейший теоретико-насыщенный текст о настоящем и будущем науки и аналитики, учебник, учащий самостоятельно мыслить, думать, исследовать, познавать и качественно облекать результаты познания в какие-то релевантные формы.

Авторам удачно удалось выйти далеко за пределы ставшего уже банальным формата наставления для аспирантов и магистрантов относительно написания диссертации и оформления стопок связанных с нею бумаг (такого «добра» вышло уже много), этот труд более рассчитан на, что называется, продвинутых пользователей.

В учебнике (в главе третьей под названием «Методы научных исследований и прикладной аналитики») сжато, но очень ёмко излагаются, объяснены многие исследовательские методы, общее понимание которых у большинства магистрантов, да и у аспирантов тоже сводится к «да, есть такой, что-то слышали и даже пару раз читали». Редкий случай, когда представляется такой компендиум (от лат. compendium - взвешивать вместе от com- «вместе» и pendere «взвешивать»; сокращённое ёмкое изложение основных положений) исследовательских методов. Перечислим: методы анализа и синтеза, дедуктивный и индуктивный методы, абдуктивный и иные методы оперирования гипотезами, методы формализации и конкретизации, аксиоматический метод, методы классификации, моделирования, аппроксимации, сравнения, аналогии, методы абстрагирования и идеализации, метод проб и ошибок, метод обобщения, методы цитирования. Четвертая глава под названием «Некоторые специальные методы аналитики» даёт описания нескольких специальных методов аналитики.

Осведомленность о предпосылках и составляющих хорошего научного исследования, понимание этого всего гарантирует, что эта работа будет на высоте и поможет определить её успех и признание. И качественное владение описанными в этом учебнике методами - залог успеха, но лишь отчасти, есть еще нечто, в существенной мере предопределяющее, образно говоря, что качественно написанная картина станет не просто полотном с успешно наложенными красками, а именно шедевром.

Но опять же, что даёт основания счесть исследование «хорошим», успешно состоявшимся, «высококлассным»?

И вот этот раздел учебника - часть главы первой под названием «Онтология научных исследований и прикладной аналитики» (параграфы с 1.6 по 1.10) - содержит попытку (и довольно успешную) объяснить то, до чего смогли докопаться авторы: критерии и показатели 1) содержательной глубины исследования, 2) сложности исследования, 3) научной ценности, 4) научной значимости исследования, 5) ясности исследования, 6) целостности исследовательского произведения, давая колоссальный объём поводов заду-маться даже профессионалам в научных и прикладных аналитических исследованиях пе-реосмыслить знакомое, увидеть много нового, понять всё много более глубоко и более широко. Ничего подобного прочесть более в российской научной литературе просто негде, а сам материал хорош.

Предваряющие этот блок параграфы первой главы тоже вносят свою очень существенную лепту, объясняя различия между наукой и прикладной аналитикой, и суть каждого из этих понятий (параграфы 1.1 и 1.2), объясняя понятие научного концепта (параграф 1.3) и понятие дизайна научного произведения (параграф 1.4), объясняя, с чего 
«стартуют» в научном исследовании (параграф 1.5), давая уникальную содержательнонасыщенную объяснительную и инструктивную информацию.

Достраивает авторский концепт компоновки учебника глава вторая с названием «Язык науки и прикладной аналитики», объясняющая, что есть индивидуальный стиль научного письма (параграф 2.1), инженерный стиль научного письма с присущими ему короткими формулировками в научном и прикладном аналитическом исследовании (параграф 2.3), раскрывающая очень непростую и весьма дискуссионную тему сложной научной лексики и сложных конструкций формулировок в научном и прикладном аналитическом исследовании (параграф 2.2).

От «обычных» работ по обучению технологиям науки обозреваемый труд кардинально в лучшую сторону отличен полным отсутствием «воды» псевдофилософствования, «переливания из пустого в порожнее», что так претит представителям точных, технических наук. Учебник написан очень живо и по существу, хотя и весьма сухим стилем (что есть явное достоинство), и при этом учебник перенасыщен научнометодологическим объяснительным материалом (что также есть явное достоинство). В немалой степени это определяется тем, что авторы - уже состоявшиеся учёные с огромным багажом научных публикаций у каждого, в основу учебника положен курс лекций, читавшийся И.В. Понкиным в течение многих лет и воплощенный в подготовку многочисленных учеников - кандидатов и докторов юридических наук.

Однако же, надо сказать, стиль изложения рассчитан на уже квалифицированного читателя, и для самостоятельного изучения книги требуется определённый уровень подготовленности и некоторый уже существенный уровень познаний в научной методологии. Перед нами скорее учебник не столько для аспирантов, сколько для их научных руководителей - «книга для учителя» (есть такие жанр и формат).

Многие материалы учебника ранее можно было найти лишь в специальных журналах или в усложненных значительными математическими аппаратами узкотематиче-ских изданиях, раскрытие ряда тематических блоков учебника ранее вообще не публико-валось.

Недостатки обозреваемого учебника сформулируем по-инженерному кратко.

Первой главе совершенно недостаёт раздела под ориентировочным названием «Параметр полноты охвата и полноты учёта определяющих факторов» и раздела о черновых первичных проходах в научном исследовании на ранних его этапах (в разделе о методе проб и ошибок есть немного, но нужен самостоятельный раздел). Второй главе недостаёт описаний других специфических стилей научного письма, перечень которых явно не исчерпывается инженерным стилем, оперирующим короткими формами, и неназванным персонально в учебнике стилем (что тоже недостаток), оперирующим усложненными модальностями и формами. Третьей главе недостаёт описаний многих методов, во всяком случае - метода объяснения. Четвертая глава явно ждёт дополнения числа описанных специфических методов.

Впрочем, это всё - всего лишь пожелания на будущее, но явно не отражение критических недостатков. Этот яркий и мощный учебник (мануал, как любит говорить поколение миллениа-лов) способен очень существенно изменить в лучшую сторону всю систему подготовки учёных и прикладных аналитиков.

\section{ИНФОРМАЦИЯ ОБ АВТОРЕ}

Морева Светлана Леонидовна, кандидат технических наук, доцент кафедры управления в технических системах СанктПетербургского государственный университета аэрокосмического приборостроения (ГУАП)

\section{INFORMATION ABOUT THE AUTHOR}

Svetlana L. Moreva, candidate of technical Sciences, associate Professor of the Department of management in technical systems of the Saint Petersburg state University of aerospace instrumentation (GUAP) 